\title{
Quantum Investigation (NMR and Electronic Properties) of SWCNT $(6,6)$ with 5-Fluorouracil as Nano Carrier
}

\author{
NASIM SHADMANI ${ }^{*}$ \\ Department of Chemistry, Science and Research Branch, Islamic Azad University, Tehran, Iran. \\ ${ }^{*}$ Corresponding author E-mail: n.shadmani@gmail.com \\ http://dx.doi.org/10.13005/ojc/330516
}

(Received: April 10, 2017; Accepted: June 01, 2017)

\begin{abstract}
Nowadays, the use of nanotube is widely spread in the field of drug delivery. In this work, bind between SWCNT $(6,6)$ with 5 -fluorouracil were investigated using DFT in the gas phase at $298.15 \mathrm{~K}$ and $1 \mathrm{~atm}$. Density function theory parameters were carried out with Gaussian 98 by M062X/6-31G** standard basis set. The NBO analysis and electronic properties have calculated from composites $A, B$, and $C$. The calculated magnetic shielding tensor $\left(\sigma_{\text {iso }}\right.$ and $\left.\sigma_{\text {aniso }}, p p m\right)$ studied for $\mathrm{C}, \mathrm{H}, \mathrm{N}, \mathrm{F}$ and $\mathrm{O}$ nuclei in the active site of for composites $\mathrm{A}, \mathrm{B}$, and $\mathrm{C}$. The results are shown composite $\mathrm{C}$ more stable than others.
\end{abstract}

Key word: Carbon nanotube, 5-Fluorouracil, DFT, NBO, NMR.

\section{INTRODUCTION}

5-Fluorouracil was called 5-fu in 1957. 5 -Fu used from us food and drug administration for cancer chemotherapy as an antitumor, anti-metabolic agent. 5-Fu used to treat different cancer, including breast, bowel, skin, stomach, gullet, and pancreatic cancer. The common chemical synthesis of 5- fu were reported by Heidelberger and Duschinsky et al in $1997^{1,3}$. Nanotechnology is based on the use of phenomena on a nanometer in at field such as nanoparticle, nanotube, nano composite, nano fibers, mesoporous silica, graphene, fluorourene, liposome, $\beta$-yclodextrines, calixarenes, and polymers in the pharmaceutical

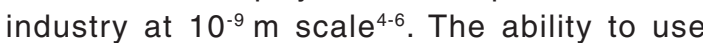

nanotechnology to alter the characteristic of a drug to increase solubility, decrease degradation during site of action promises to increase efficacy with decreasing unwanted side effects. The recent years of used various nanostructures like nanotube (SWCNT and MWCNT) such as drug delivery systems. Carbon nanotubes have been studied one dimensional nanostructure, including carbon and hydrogen atoms with $\mathrm{sp}^{2}$ hybrid in hexagonal lattice structure $^{7,0}$. Carbon nanotubes are synthesis arc discharge method, laser ablation and thermal chemical vapor deposition (CVD) method, respectively ${ }^{11,12}$. Nanotubes are two types of : singlewalled carbon nanotube (SWCNT) and multi-walled carbon nanotube (MWCNT), respectively. The structure of SWCNT inclusion, armchair $(m=n)$, 
zigzag $(n \neq 0, m=0)$, chiral $(m \neq 0$, and $m \neq n)$, respectively ${ }^{13-14}$. An important application of nanotubes was studied in fields such as electronic, mechanical, thermal, catalyst support too many biological, emission, chemical sensor, drug delivery ${ }^{15-16}$. A simplified 3D model of armchair (6, 6) SWCNT of about $6 \AA$ in length with a diameter of about $6 \AA$ (84 atoms) was built with the nanotube modeler package ${ }^{17}$. In the paper, we were studied SWCNT $(6,6)$ type of armchair and 5-F as a new drug carrier system.

\section{Computational method}

All calculation was carried out using Gussian $98^{18}$ and Nanotube Modeler package. The geometry of the composite A, composite B, composite $\mathrm{C}, 5$-fu and $\mathrm{SWCN}^{6,6}$ were carried out M062X method ${ }^{19}$ with $6-31 \mathrm{G}^{* *}$ basis set of theory ${ }^{20}$. The first optimizing both the isolated 5 -fu and $\operatorname{SWCNT}(6,6)$, and then we optimized 5-fu connect to SWCNT at three sites $A, B, C$ that they showed in Fig. 1. The after geometry optimization also we allowed to calculate the vibrational frequencies and nuclear magnets spectra, NBO analysis for and SWCNT(6,6) compounds, respectively. In the next step, we investigated hardness, softness, Dipole moment (Debby), Ionization energy, electron affinity, potential chemistry, electrophilic, electronegativity, maximum amount of electronic charge and gap energy using the M062X method, and $6-31 G^{\star *}$ basis set standard at $298.15 \mathrm{k}$ for 5-fu, composite A, composite $\mathrm{B}$, and composite $\mathrm{C}$, respectively. composite A, composite B, composite C, 5-fu,

\section{RESULT AND DISCUSSION}

DFT method has been widespread used in the studies of organic, inorganic material and super molecular, nanomaterial, and interaction drug with DNA, RNA, acid amine, calixarenes, nanotube, fullerene, graphene, and other molecular at many years $\mathrm{ago}^{21-23}$. The $\mathrm{QM} / \mathrm{MM}$ total energy was calculated such as the sum of the DFT energy, the MM energy, and the DFT/MM interaction energy.

$\mathrm{E}^{\text {total }}=\mathrm{E}_{\mathrm{DFT}}+\mathrm{E}_{\mathrm{MM}}+\mathrm{E}_{\mathrm{DFT} / \mathrm{MM}}$

$E_{M M}, E_{D F T}$, and $E_{D F T / M M}$ were discussed for the $M M, Q M$, and MM/QM subsystems, respectively. NMR spectroscopy is a research technique that exploits the magnetic properties of certain atomic nuclei to determine physical and chemical properties of atoms or the molecules in which they are contained. It relies on the phenomenon of nuclear magnetic resonance and can provide detailed information about the structure, dynamics, reaction state, and chemical environment of molecules ${ }^{24-25}$. Ab initio calculation of nuclear magnetic shielding has become an aid in the analysis of molecular structure and accurate assignment of NMR spectra of compounds ${ }^{26-28}$. So, NMR is based on the quantum mechanical property of nuclei. The chemical shielding refers to the phenomenon, which is associated with the secondary magnetic field created by the induced motions of the electrons that surrounding the nuclei when in the presence of an applied magnetic field ${ }^{29}$. In general, the electron distribution around a nucleus in a molecule is more spherically symmetric. Therefore, the size of the electron current around the field, and hence the size of the shielding, will depend on the orientation of the molecule within the applied field $\mathrm{B}_{0}{ }^{30-33}$
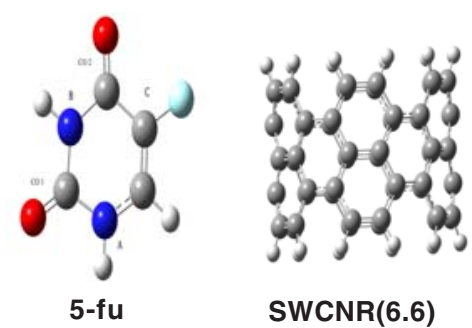

$\operatorname{SWCNR}(6.6)$
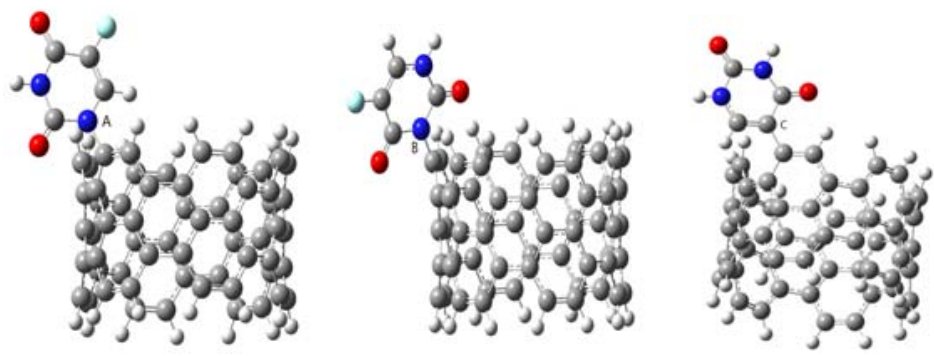

Composite B

Fig.1.Optimized structures of the 5-fu, SWCNT, Composites A, B, and C. 


\section{Nuclear Magnetic Resonance Parameters}

In the present study, total dipole moments of 5-fu interaction with SWCNT in gas phase have been explored and NMR computations were done by Gaussian 98 suite of programs. The calculated magnetic shielding tensor ( $\sigma_{\text {iso }}$ and $\sigma_{\text {aniso }}$,ppm) calculated for $\mathrm{C}, \mathrm{H}, \mathrm{N}, \mathrm{F}$ and $\mathrm{O}$ nuclei in the active site of 5-fu and for carbon atoms of the open end of a SWCNT system in the gas phase are presented for composites A, B and C at Table 1, 2 and 3. As was expected, the NMR shielding tensors of $\mathrm{H}, \mathrm{C}$, $\mathrm{N}, \mathrm{F}$ and $\mathrm{O}$ nuclei are drastically affected by the atom to which they are bonded and by the type of the bond to the neighboring atom. The results obtained give strong evidence that intermolecular interactions play a very important role in determining the $\mathrm{H}, \mathrm{C}, \mathrm{N}, \mathrm{F}$ and $\mathrm{O}$ NMR chemical shielding tensors. Some systematic trends appeared from the analysis of the calculated values. Isotropic and anisotropic chemical shielding is one of the other parameters that were checked in this work. The results of investigating chemical shift tensor indicate that $84 \mathrm{~F}, 3 \mathrm{C}$, and $3 \mathrm{C}$ have been shown to be the largest value of $\sigma$ is in system as drug interacted with SWCNT and our knowledge about drug interacted to SWCNT has been specified that $9{ }^{\circ} \mathrm{C}$, 940 and $85^{\circ} \mathrm{C}$ show the largest intermolecular effects on $\left(\sigma_{\text {aniso }}\right)$ component. These results are shown in tables 1,2 , and 3 for composites $A, B$, and $C$, respectively.

\section{Natural Bond Orbital analysis (NBO)}

We investigated the parameters, such as donor, acceptor, type bond, hyper conjugations energy $\left(E^{2}\right)$ and occupancy by DFT at M062X and $6-31 G^{* *}$ standard basis set and are shown at Table 4. In the 5-FU, charge transfer was done at $L p(1)$ $\mathrm{N} 1$ to $\pi^{\star} \mathrm{C} 2-\mathrm{O} 9$ with maximum hyper conjugations energy approximate $59.29 \mathrm{ev}$, hybrid $\mathrm{sp}^{1.00}$, and occupancy 1.64887, respectively. In the composite $A$, charge transfer was done at $L p(1) N 88$ to $\pi^{\star} C 85$ C86 with maximum hyper conjugations energy approximate $38.02 \mathrm{ev}$, hybrid $\mathrm{sp}^{99,99}$, and occupancy 1.63452, respectively. In the composite $\mathrm{B}$, charge transfer was done in Lp(1) N92 to $\pi^{\star}$ C90-094 with maximum hyper conjugations energy approximate 46.49ev, hybrid $\mathrm{sp}^{99,99}$, and occupancy 1.63289 , respectively. In the composite $\mathrm{C}$, charge transfer was done at $\pi^{*}$ C84-C85 to $\pi^{\star}$ C29-C30 with maximum hyper conjugations energy approximate 17.59ev, hybrid $\mathrm{sp}^{99,99}$, and occupancy 0.23732 , respectively. These results are shown in table 6 for composites $\mathrm{A}, \mathrm{B}$, and $\mathrm{C}$, respectively.

\section{Electronic properties}

The quantum concepts such as chemical potential $(\mu)$, hardness $(h)$, dipole moment (D), softness (s), ionization potential (I), electron affinity $(A)$, electrophilic $(\omega)$ electronegativity $(\chi)$, and the maximum amount of electronic charge $\left(\Delta N_{\text {max }}\right)$ was obtained in this paper by Eq.2 to Eq.8.

$$
\begin{aligned}
& \mathrm{I}=-\quad \text { номо } \\
& \mathrm{A}=-\quad \text { LUмо } \\
& \mathrm{h}=(\mathrm{I}-\mathrm{A}) / 2 \\
& \mu=-\chi=-(\mathrm{I}+\mathrm{A}) / 2 \\
& \mathrm{~S}=1 / 2 \mathrm{~h} \\
& \omega=+\left(\mu^{2} / 2 \mathrm{~h}\right) \\
& \Delta \mathrm{N}_{\max }=-\mu / \mathrm{h}
\end{aligned}
$$

The value of the dipole moment of 5 -fu, SWCNT, composites A, B, and C are obtained at rank 3.9814, 0, 6.2014, 2.9639, and 3.1896, respectively. In fact, the high dipole moment was shown the high reactively of total compound. Dipole moments are used as descriptive to depict the charge movement across the molecule. The dipole moment vector in a molecule was shown the centers of positive and negative charge. The values of $\div, \mathrm{h}$ was obtained such as little electron transferred, $\Delta \mathrm{N}_{\text {max }}$, transferred electron from 5-fu to ever composites $\mathrm{A}, \mathrm{B}$, and $\mathrm{C}$, respectively. A positive value of $\Delta \mathrm{N}_{\max }$ shown the transfer charge from 5-fu to composite A, B and C. Composites A, B, and C acts as an electron acceptor, and 5 -fu acts as an electron donor. The values of $\Delta \mathrm{N}_{\max }$ of 5 -fu, composites A, B, C are 1.5091, 3.7658, 3.5329, and 3.5630 , respectively. The values of $h$ for 5 -fu, composites A, B, and C are 0.09937, 0.03468, 0.03470 , and 0.033479 , respectively. The value $h$ was reduced from 5 -fu to composites $A, B$, and $C$ after formation complex. Therefore, 5 -fu is hardness structure, and composite $B$ is softer than others. The values of $\div$ for 5 -fu, composites $A, B$, and $C$ are $0.14989,0.13060,0.12263$, and 0.12397 , respectively. 5 -fu is acceptor electron and composites $\mathrm{A}, \mathrm{b}$, and $\mathrm{C}$ are donor electron. The value of chemical potential was obtained 
$-0.629,-0.548,-0.515$, and -0.521 for $5-f u$, composites $\mathrm{A}, \mathrm{B}$, and $\mathrm{C}$, respectively. The negative value chemical potential was shown the formation of complexes between 5-fu and SWCNT at three sites $A, B$, and $C$. These results are shown in table 7 for $5-\mathrm{Fu}$, composites $A, B$, and $C$, respectively. The minimum energy structure has maximum hardness and maximum chemical potential, respectively. Therefore, values of energy, hardness, and chemical potential are $-7413719.968 \mathrm{kJmol}^{-1}, 0.03479$, and -0.521 for composite $\mathrm{C}$, respectively. The values of energy, hardness, and chemical potential are $-1354536.019 \mathrm{kJmol}^{-1}, 0.0993$, and -0.629 for 5 -fu, respectively. The value of electrophilic was obtained $0.11311,0.2459$, 0.21662 , and 0.22086 for 5 -fu, composites $A$, $B$, and $C$. The composite $A$ has highest properties electrophilic then another. The value of ionization potential was obtained 0.2492 $0.1653,0.15734$, and 0.15877 for 5 -fu, composites $A, B$, and $C$, respectively. The highest ionization potential has 5-fu, and between composites, composite A. The compounds have higher ionization potential unstable then another. The compounds have a more positive value of electron affinity than another are often called on electron acceptor and the less positive an electron donor. Electron affinities have an important role at octet and filled valence shells. The values of electron affinity for 5-fu, composites A, B, and C are $0.0506,0.09592,0.08792$, and 0.08918 . Therefore, composites A, B, and C are acceptor electron and 5-fu is donor electron, respectively. In order to check the validity of this description about the compound stability of the different species in the 5-fu and 5-fuSWCNT ( $A, B$, and C), the HOMO-LUMO frontier orbits were calculated. The band gap can be described that compound stability and semi-conducting properties, respectively. The compound with the highest band gap, highest stability, and lowest semiconducting was reported at 5-fu, A, B and C, respectively. As a whole, the band gap for 5-fu, A, B and C compound were reported in rang $0.198752,0.06936,0.06942$, and 0.06959 (ev), respectively. The highest value band gap was observed 0.06591 at site C, which was shown at table1. Table7 and Fig.2 are shown HOMO orbital, LUMO orbital, HOMO-LUMO band gap values, and orbits schemes for 5-fu, SWCNT, composites A, B and $C$, respectively. Therefore, the grater energy gap belongs to the between composites for composite $\mathrm{C}$.

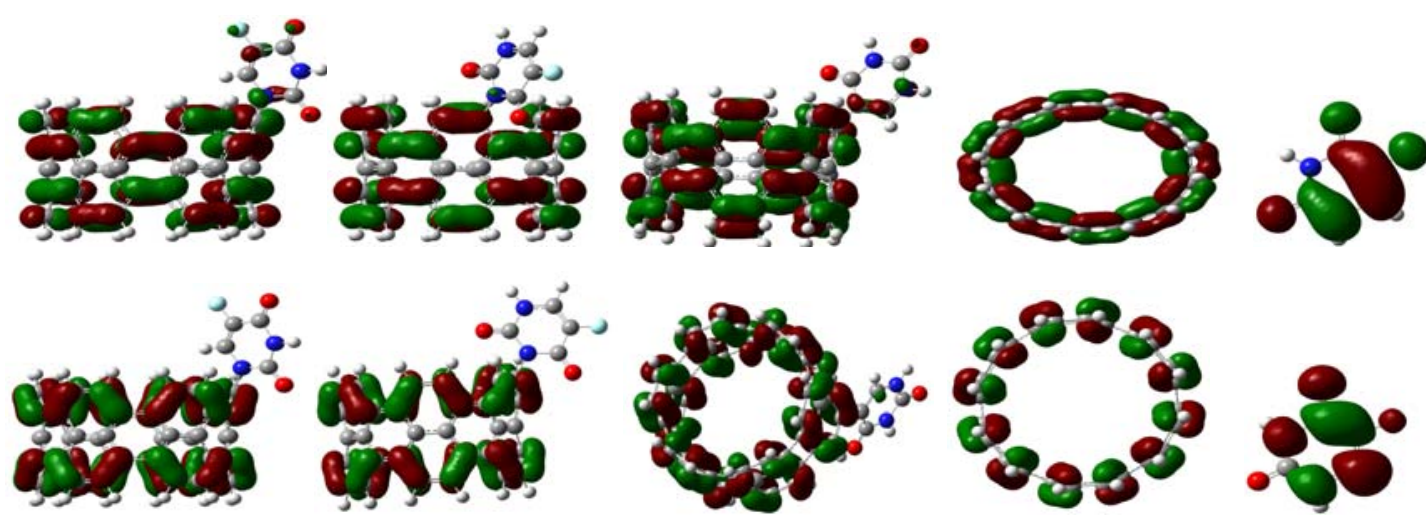

Fig.2. The calculated orbits of HOMO (upper) and LUMO (lowest) for composites A, B, and C, SWCNT $(6,6)$, and 5-fu, respectively. 
Table.1: Components of the magnetic shielding tensor $\left(\sigma_{\text {iso }}\right.$ and $\left.\sigma_{\text {aniso }}\right)$ calculated for composite A.

\begin{tabular}{|c|c|c|c|c|c|}
\hline Atom & $\sigma_{\text {iso }} \sigma_{\text {aniso }}$ & $\sigma_{11} \sigma_{22} \sigma_{33}$ & Atom & $\sigma_{s o} \sigma_{\text {aniso }}$ & $\sigma_{11} \sigma_{22} \sigma_{33}$ \\
\hline \multirow[t]{2}{*}{$3 C$} & 75.94 & -2.82 & & & 30.9 \\
\hline & 163.45 & 70.01 & $84 \mathrm{~F}$ & 351.75 & 308.05 \\
\hline \multirow{2}{*}{$9 \mathrm{C}$} & 73.66 & $\begin{array}{c}160.63 \\
-13.3\end{array}$ & & 112.04 & $\begin{array}{c}327.1 \\
420.09\end{array}$ \\
\hline & 184.73 & $\begin{array}{c}62.87 \\
171.43\end{array}$ & $85 C$ & $\begin{array}{c}52.08 \\
-103.74\end{array}$ & $\begin{array}{c}100.66 \\
58.67\end{array}$ \\
\hline $10 \mathrm{C}$ & $\begin{array}{c}75.88 \\
180.52\end{array}$ & $\begin{array}{l}-9.86 \\
66.86\end{array}$ & $86 C$ & 64.13 & $\begin{array}{c}-3.08 \\
131.94\end{array}$ \\
\hline $17 \mathrm{C}$ & $\begin{array}{c}75.04 \\
182.3 \\
171.22\end{array}$ & $\begin{array}{c}170.66 \\
-11.08 \\
64.97\end{array}$ & $\begin{array}{c}87 C \\
-142.53\end{array}$ & $\begin{array}{c}-147.59 \\
\\
42.45 \\
75.12\end{array}$ & $\begin{array}{c}76.11 \\
-15.65 \\
97.38\end{array}$ \\
\hline \multirow[t]{2}{*}{$23 C$} & 74.19 & -11.92 & & & -45.15 \\
\hline & 183.17 & 63.25 & $88 \mathrm{~N}$ & 112.75 & 166.1 \\
\hline $29 \mathrm{C}$ & $\begin{array}{c}74.4 \\
183.09\end{array}$ & $\begin{array}{c}171.25 \\
-11.76 \\
63.65\end{array}$ & $89 \mathrm{H}$ & $\begin{array}{l}-122.9 \\
23.96\end{array}$ & $\begin{array}{c}128.95 \\
43.2 \\
20.29\end{array}$ \\
\hline $30 \mathrm{C}$ & $\begin{array}{c}74.76 \\
182.29\end{array}$ & $\begin{array}{c}171.33 \\
-11.14 \\
64.3 \\
171.15\end{array}$ & $90 \mathrm{~N}$ & $\begin{array}{c}7.5 \\
98.21 \\
-91.24\end{array}$ & $\begin{array}{c}23.81 \\
27.79 \\
129.67 \\
126.54\end{array}$ \\
\hline $37 C$ & $\begin{array}{c}74.38 \\
183.18\end{array}$ & $\begin{array}{c}-11.79 \\
63.54 \\
171.39\end{array}$ & 910 & $\begin{array}{l}-56.23 \\
722.75\end{array}$ & $\begin{array}{c}38.43 \\
-371.56 \\
-148.33\end{array}$ \\
\hline \multirow[t]{2}{*}{$43 C$} & $\begin{array}{c}74.67 \\
183.45\end{array}$ & $\begin{array}{c}-11.86 \\
64.29\end{array}$ & $92 \mathrm{C}$ & 52.07 & $\begin{array}{c}351.19 \\
94.61\end{array}$ \\
\hline & & 171.59 & & -122.01 & 89 \\
\hline \multirow[t]{3}{*}{$49 C$} & 75.23 & -12.03 & & & -27.4 \\
\hline & 182.02 & 67.75 & $93 \mathrm{H}$ & 25.87 & 29.83 \\
\hline & & 169.99 & & -8.44 & 26.38 \\
\hline \multirow[t]{3}{*}{$50 \mathrm{C}$} & 73.87 & -13.55 & & & 21.39 \\
\hline & 184.19 & 64.53 & $94 \mathrm{H}$ & 12.83 & -180.72 \\
\hline & & 170.64 & & & -81.63 \\
\hline \multirow[t]{2}{*}{$71 \mathrm{H}$} & 24.18 & 18.73 & & & 300.87 \\
\hline & 12.17 & 22.93 & & & \\
\hline
\end{tabular}


Table. 2: Components of the magnetic shielding tensor $\left(\sigma_{\text {iso }}\right.$ and $\left.\sigma_{\text {aniso }}\right)$ calculated for composite B.

\begin{tabular}{|c|c|c|c|c|c|}
\hline Atom & $\sigma_{\text {iso }} \sigma_{\text {aniso }}$ & $\sigma_{11} \sigma_{22} \sigma_{33}$ & Atom & $\sigma_{\text {iso }} \sigma_{\text {aniso }}$ & $\sigma_{11} \sigma_{22} \sigma_{33}$ \\
\hline \multirow[t]{3}{*}{$\overline{3 C}$} & 74.9 & -12.21 & & -105.14 & 60.97 \\
\hline & 82.85 & 66.3 & $88 \mathrm{C}$ & 49.03 & 93.37 \\
\hline & & 170.63 & & -125.92 & 86.29 \\
\hline \multirow[t]{3}{*}{$9 \mathrm{C}$} & 74.8 & -11.14 & & & -32.55 \\
\hline & 182.39 & 64.3 & $89 \mathrm{H}$ & 26.24 & 21.01 \\
\hline & & 171.24 & & 10.84 & 25.86 \\
\hline \multirow[t]{3}{*}{$10 \mathrm{C}$} & 74.65 & -11.78 & & & 31.86 \\
\hline & 183.16 & 64.39 & $90 \mathrm{C}$ & 41.94 & 93.68 \\
\hline & & 171.37 & & -138.96 & 77.43 \\
\hline \multirow[t]{3}{*}{$17 \mathrm{C}$} & 74.7 & -11.19 & & & -45.27 \\
\hline & 182.38 & 64.09 & $85 \mathrm{C}$ & 74.07 & 149.33 \\
\hline & & 171.19 & & -155.6 & 79.14 \\
\hline \multirow[t]{3}{*}{$23 \mathrm{C}$} & 74.81 & -10.72 & & & -6.26 \\
\hline & 181.84 & 64.12 & $86 \mathrm{~N}$ & 141.01 & 178.37 \\
\hline & & 171.11 & & -103.01 & 169.3 \\
\hline \multirow[t]{3}{*}{$29 \mathrm{C}$} & 74.8 & -11.13 & & & 75.35 \\
\hline & 182.37 & 64.31 & $87 C$ & 52.62 & 101.02 \\
\hline & & 171.24 & & -105.14 & 60.97 \\
\hline \multirow[t]{3}{*}{$30 \mathrm{C}$} & 74.58 & -11.3 & & & -4.11 \\
\hline & 182.44 & 63.9 & $88 C$ & 49.03 & 93.37 \\
\hline & & 171.14 & & -125.92 & 86.29 \\
\hline \multirow[t]{3}{*}{$49 \mathrm{C}$} & 66.09 & 128.46 & & & -32.55 \\
\hline & -142.74 & 84.08 & $89 \mathrm{H}$ & 26.24 & 21.01 \\
\hline & & -14.27 & & 10.84 & 25.86 \\
\hline \multirow[t]{3}{*}{$50 \mathrm{C}$} & 71.3 & -9.86 & & & 31.86 \\
\hline & 173.96 & 59.67 & $90 \mathrm{C}$ & 41.94 & 93.68 \\
\hline & & 164.09 & & -138.96 & 77.43 \\
\hline \multirow[t]{3}{*}{$71 \mathrm{H}$} & 23.88 & 18.65 & & & -45.27 \\
\hline & 11.53 & 22.82 & $91 \mathrm{~F}$ & 348.74 & 304.42 \\
\hline & & 30.18 & & 109.53 & 327.83 \\
\hline \multirow[t]{3}{*}{$84 \mathrm{H}$} & 25.47 & 27.68 & & & 413.96 \\
\hline & -4.66 & 25.72 & $92 \mathrm{~N}$ & 73.37 & 13.8 \\
\hline & & 23.02 & & 122.87 & 69.65 \\
\hline \multirow[t]{3}{*}{$85 \mathrm{C}$} & 74.07 & 149.33 & & & 136.67 \\
\hline & -155.6 & 79.14 & 930 & 18.4 & -164.92 \\
\hline & & -6.26 & & -468.68 & -83.6 \\
\hline \multirow[t]{3}{*}{$86 \mathrm{~N}$} & 141.01 & 178.37 & & & 303.75 \\
\hline & -103.01 & 169.3 & 940 & -82.34 & -435.7 \\
\hline & & 75.35 & & 789.91 & -165.5 \\
\hline $87 C$ & 52.62 & 101.02 & & & 354.19 \\
\hline
\end{tabular}


Table. 3: Components of the magnetic shielding tensor $\left(\sigma_{\text {iso }}\right.$ and $\left.\sigma{ }_{\text {aniso }}\right)$ calculated for composite $c$.

\begin{tabular}{|c|c|c|c|c|c|}
\hline Atom & $\sigma_{\text {iso }} \sigma_{\text {aniso }}$ & $\sigma_{11} \sigma_{22} \sigma_{33}$ & Atom & $\sigma_{\text {iso }} \sigma_{\text {aniso }}$ & $\sigma_{11} \sigma_{22} \sigma_{33}$ \\
\hline \multirow[t]{3}{*}{$3 C$} & 74.8 & -10.91 & $71 \mathrm{H}$ & 23.77 & 19.483 \\
\hline & -182.02 & 64.21 & & -9.207 & 23.13 \\
\hline & & 171.11 & & & 28.69 \\
\hline \multirow[t]{3}{*}{$9 \mathrm{C}$} & 74.85 & -11.82 & $84 \mathrm{C}$ & 78.52 & 14.78 \\
\hline & -183.22 & 64.97 & & -145.69 & 60.31 \\
\hline & & 171.4 & & & 160.47 \\
\hline \multirow[t]{3}{*}{$10 \mathrm{C}$} & 74.3 & -11.71 & $85 \mathrm{C}$ & 56.58 & 142.87 \\
\hline & -182.92 & 63.42 & & 174.36 & 58.37 \\
\hline & & 171.21 & & & -31.49 \\
\hline \multirow[t]{3}{*}{$17 \mathrm{C}$} & 73.97 & -13.18 & $86 \mathrm{C}$ & 37.22 & 96.84 \\
\hline & -184.31 & 63.96 & & 144.38 & 62.38 \\
\hline & & 171.135 & & & -47.54 \\
\hline \multirow[t]{3}{*}{$23 C$} & 73.05 & -13.52 & $87 \mathrm{~N}$ & 126.56 & 172.21 \\
\hline & -181.55 & 64.63 & & 119.06 & 154.33 \\
\hline & & 168.03 & & & 53.15 \\
\hline \multirow[t]{3}{*}{$29 \mathrm{C}$} & 71.58 & -9.88 & $88 \mathrm{H}$ & 25.31 & 19.79 \\
\hline & -181.46 & 53.05 & & 0 & 23.18 \\
\hline & & 171.58 & & & 32.96 \\
\hline \multirow[t]{3}{*}{$30 \mathrm{C}$} & 70.58 & -0.56 & $89 N$ & 97.4 & 129.28 \\
\hline & -156.29 & 56.58 & & 92.5 & 126.15 \\
\hline & & 155.73 & & & 36.78 \\
\hline \multirow[t]{3}{*}{$37 \mathrm{C}$} & 73.02 & -14.71 & 900 & -58.8 & -351.55 \\
\hline & -186.46 & 62.03 & & 0 & -152 \\
\hline & & 171.75 & & & -351.55 \\
\hline \multirow[t]{3}{*}{$43 C$} & 73.95 & -13.04 & $91 \mathrm{C}$ & 52.7 & 97.28 \\
\hline & -184.55 & 63.38 & & 126.89 & 90.43 \\
\hline & & 171.51 & & & -29.61 \\
\hline \multirow[t]{3}{*}{$49 \mathrm{C}$} & 74.62 & -11.32 & $92 \mathrm{H}$ & 26.46 & 31.17 \\
\hline & -182.45 & 64.07 & & 10.18 & 27.22 \\
\hline & & 171.13 & & & 20.99 \\
\hline \multirow[t]{3}{*}{$50 \mathrm{C}$} & 74.4 & -11.7 & $93 \mathrm{H}$ & 25.52 & 28.78 \\
\hline & -182.86 & 63.75 & & 6.95 & 25.97 \\
\hline & & 171.16 & & & 21.83 \\
\hline \multirow[t]{2}{*}{$57 \mathrm{C}$} & 74.38 & -11.33 & 940 & 29.52 & -131.61 \\
\hline & -182.36 & 63.45171 .03 & & -425.57 & -73.78293 .96 \\
\hline
\end{tabular}


Table. 4: Parameters of NBO calculated from 5-fu, composites A, B, and C, respectively.

\begin{tabular}{|c|c|c|c|c|c|c|c|c|}
\hline parameter & Donor & Type & Acceptor & Type & Occupancy & hybrid & $E^{2}$ & $\Sigma \mathrm{E}^{2}$ \\
\hline \multirow[t]{13}{*}{ Composite A } & C57-N88 & $\sigma$ & C2-C3 & $\sigma^{*}$ & 1.97914 & $\mathrm{sp}^{2.85}$ & 1.92 & 65.19 \\
\hline & & & C2-C57 & $\sigma^{*}$ & & & 1.37 & \\
\hline & & & C55-C57 & $\sigma^{*}$ & & & 0.85 & \\
\hline & & & C55-C60 & $\sigma^{*}$ & & & 1.18 & \\
\hline & & & C85-C86 & $\sigma^{*}$ & & & 1.83 & \\
\hline & & & C86-N88 & $\sigma$ & & & 1.88 & \\
\hline & & & N88-C92 & $\sigma^{*}$ & & & 1.53 & \\
\hline & & & N90-C92 & $\sigma^{\star \star}$ & & & 2.30 & \\
\hline & $\operatorname{Lp}(1) N 88$ & $\sigma$ & C2-C57 & $\sigma^{*}$ & 1.63452 & $\mathrm{sp}^{99.99}$ & 4.19 & \\
\hline & & & C3-C57 & $\pi^{\star}$ & & & 5.41 & \\
\hline & & & C49-H88 & $\sigma^{*}$ & & & 0.51 & \\
\hline & & & C55-C57 & $\sigma^{*}$ & & & 4.20 & \\
\hline & & & C85-C86 & $\pi^{\star}$ & & & 38.02 & \\
\hline \multirow[t]{19}{*}{ Composite B } & C49-N92 & $\sigma$ & C48-C50 & $\sigma^{*}$ & 1.97813 & $\mathrm{sp}^{2.85}$ & 1.93 & 78.94 \\
\hline & & & C49-C50 & $\sigma^{*}$ & & & 1.42 & \\
\hline & & & C49-C56 & $\sigma^{*}$ & & & 0.76 & \\
\hline & & & C54-C56 & $\sigma^{*}$ & & & 1.17 & \\
\hline & & & N86-C88 & $\sigma^{\star}$ & & & 2.59 & \\
\hline & & & C87-C90 & $\sigma^{*}$ & & & 1.90 & \\
\hline & & & C88-N92 & $\sigma^{*}$ & & & 1.56 & \\
\hline & & & C90-N92 & $\sigma^{*}$ & & & 1.29 & \\
\hline & C90-N92 & $\sigma$ & C49-C50 & $\sigma^{*}$ & & & 0.82 & \\
\hline & & & C49-C50 & $\pi^{*}$ & & & 1.61 & \\
\hline & & & C49-N92 & $\sigma^{*}$ & & & 1.69 & \\
\hline & $\operatorname{Lp}(1) \mathrm{N} 92$ & $\sigma$ & C49-C50 & $\sigma^{*}$ & 1.63289 & $\mathrm{sp}^{99.99}$ & 4.29 & \\
\hline & & & C49-C50 & $\pi^{*}$ & & & 3.76 & \\
\hline & & & C49-C56 & $\sigma^{*}$ & & & 4.31 & \\
\hline & & & C57-H70 & $\pi^{\star}$ & & & 0.51 & \\
\hline & & & C90-094 & $\pi^{*}$ & & & 46.49 & \\
\hline & C49-C50 & $\sigma^{\star}$ & C49-C50 & $\sigma^{*}$ & 0.21272 & $\mathrm{sp}^{99.99}$ & 1.02 & \\
\hline & & & C88-N92 & $\sigma^{*}$ & & & 0.98 & \\
\hline & & & C90-N92 & $\sigma^{*}$ & & & 0.84 & \\
\hline \multirow[t]{10}{*}{ Composite C } & С30-C84 & $\sigma$ & C27-C28 & $\sigma^{*}$ & 1.9631 & $\mathrm{sp}^{2.14}$ & 1.48 & 37.86 \\
\hline & & & C28-C30 & $\sigma^{*}$ & & & 1.7 & \\
\hline & & & C29-C30 & $\sigma^{\star}$ & & & 3.12 & \\
\hline & & & C29-C36 & $\sigma^{*}$ & & & 2.51 & \\
\hline & & & C84-C85 & $\sigma^{*}$ & & & 3.55 & \\
\hline & & & C84-C86 & $\sigma^{*}$ & & & 1.82 & \\
\hline & & & C85-N87 & $\sigma^{*}$ & & & 3.76 & \\
\hline & & & C86-N89 & $\sigma^{*}$ & & & 1.81 & \\
\hline & C29-C30 & $\pi^{\star}$ & C84-C86 & $\sigma^{*}$ & 0.21959 & $\mathrm{sp}^{99.99}$ & 0.52 & \\
\hline & C84-C85 & $\pi^{\star}$ & C29-C30 & $\sigma^{*}$ & 0.23732 & $\mathrm{sp}^{99.99}$ & 17.59 & \\
\hline
\end{tabular}


Table. 5: Parameters of electronic properties calculated for 5-fu, composites A, B, and C, respectively.

\begin{tabular}{lcccc}
\hline Parameter & 5-fu & Composite A & Composite B & Composite C \\
\hline$\sigma_{\text {номо }}$ & -0.2493 & -0.1653 & -0.1573 & -0.1587 \\
$\sigma_{\text {LUMO }}$ & -0.0506 & -0.0959 & -0.0879 & -0.08918 \\
$\mathrm{E}_{\text {gар }}$ & 1.9 & -0.02061 & -0.06942 & -0.06959 \\
$\mathrm{D}$ & 3.9814 & 6.2014 & 2.9639 & 3.1896 \\
$\mathrm{~A}$ & +0.0506 & +0.09592 & +0.08792 & +0.08918 \\
$\mathrm{I}$ & +0.2492 & +0.1653 & +0.15734 & 0.15877 \\
$\mathrm{~h}$ & 0.0993 & 0.03468 & 0.03470 & 0.03479 \\
$\mathrm{~S}$ & 101.3637 & 831.468 & 830.0242 & 825.9738 \\
$\mu$ & -0.629 & -0.548 & -0.515 & -0.521 \\
$\chi$ & +0.14989 & 0.1306 & +0.12263 & +0.12397 \\
$\omega$ & 0.11311 & 0.2459 & 0.21662 & 0.22086 \\
$\Delta \mathrm{N}$ & 1.5091 & 3.7658 & 3.5329 & 3.5630 \\
\hline
\end{tabular}

\section{CONCLUSION}

The NBO analysis, such as HOMO, LUMO, $E_{\text {gap }}$, were calculated for composites $A, B$, and $\mathrm{C}$, respectively. In the composite $\mathrm{C}$, charge transfer was done at $\pi^{\star} \mathrm{C} 84-\mathrm{C} 85$ to $\pi^{*} \mathrm{C} 29-\mathrm{C} 30$ with maximum hyper conjugations energy approximate $17.59 \mathrm{ev}$, hybrid $\mathrm{sp}^{99,99}$, and occupancy 0.23732 , respectively. The maximum value of $\kappa$ has been observed for $89 \mathrm{H}, 85 \mathrm{C}$ nuclei at composites $A$, and $B, 88 \mathrm{H}$, and 900 at composite $\mathrm{C}$.

\section{ACKNOWLEDGEMENTS}

This work was supported by Science and Research Branch of Islamic Azad University.

\section{REFERENCES}

1. Liu, H. ; Chen,J.; Shen, Q.;W. Fu.;Wu,W.; Mol. Pharm, 2010,7, 1913-1920.

2. Adson, A.; Burton, P.S.; Raub, T. J.;. Barsuhn, C. L.; Audus, K. L.; HO, N. F.; J. Pharm. Sci,1995, 84, 1223-1230.

3. Cornell, G.N.; Cahow, C.E.; Frey, C.; McSherry, C.; Beal, J.M.; Cancer Chemother Rep,1960, 9,23-30.

4. lijima, S.; Nature 1991, 354,56-58

5. Colomer, J.F.; Henrard, L.; Lambin, P.; Van Tendeloo1, G.; Phys Rev B. 2001, 64,1-7

6. Berber, S.; Kwon, S.; Tomanek, Y.K.; Phys. Rev. Lett.2000, 84, 4613-4616

7. Singh, R.; Pantarotto, D.; Lacerda, L.; Pastorin, G.; Klumpp, C.; Prato, M.; Bianco,
A.; Kostarelos, K.; Proc Natl Acad Sci USA. 2006, 103, 3357-3362.

8. White, C.T.; Todorov, T.N; Nature.1998, 393, 240-241.

9. Wong Shi Kam, N.; Jessop, T.C; Wender, P.A; Dai, H.; J. Am. Chem. Soc. 2004, 126, 68506851.

10. Pantarotto, D.; Singh, R.; McCarthy, D.; Erhardt, M.; Briand, J.P.; Prato, M.; Kostarelos, K.; Bianco, A.; Angew. Chem., Int. Ed.2004, 43, 5236-5242.

11. Petersen, J.L.; Egan, D.M.; Defense Horizons. 2002, 8, 1-6.

12. Li, H. L.; Chen, Y.; Langmuir. 2010; 26, 51355140 
13. Ajayan, P. M.; Stephan, O.; Colliex, C.; Trauth, D.; Science, 1994, 265, 1212.

14. Saito, Y.; Hamaguchi, K.; Hata, K.; Nature, 1997, 389, 554

15. DeHeer, W. A.; Chatelain, A.; Ugarte, D.; Science, 1995, 270, 1179.

16. Huang, J.Y.; Chen, S.; Ren, F.; Nanolett, 2006, 6, 1699. Uya

17. www.jcrystal.com/products/wincnt/ Nanotube, Nanotube Modeler. Version 1.2.4 (2004-2005).

18. Frisch, M.J.;Trucks, G.W.; Schlegel, H.B.;Scuseria, G.E.; Scuseria, M.A.; Cheeseman, J.R.; Zakrzewski, V.G.; Montgomery, J.A.; Stratmann, R.E.; Burant, J.C.; Dapprich, S.; Millam, J.M.; Daniels, A.D.; Kudin, K.N.; Strain, M.C.; Farkas, O.; Tomasi, J.; Barone, V.; Cossi, M.; Cammi, R.; Mennucci, B.; Pomelli, C.; Adamo, C.; Clifford, S.; Ochterski, J.; Petersson, G.A.; Ayala, P.Y.; Cui, Q.; Morokuma, K.; Malick, D.K.; Rabuck, A.D.; Raghavachari, K.; Foresman, J.B.; Cioslowski, J.; Ortiz, J.V.; Baboul, A.G.; Stefanov, B.B.; Liu, G.; Liashenko, A.;Piskorz, P.; Komaromi, I.; Gomperts, R.; Martin, R.L.; Fox, D.J.; Keith, T.; Al-Laham, M.A.; Peng, C.Y.; Nanayakkara, A.; Gonzalez, C.; Challacombe, M.; Gill, P.M.W.; Johnson, B.; Chen, W.;Wong, M.W.; Andres, J.L.; Gonzalez, C.; Head Gordon, M.; Replogle, E.S.; Pople, J.A.; GAUSSIAN 98, revision B.02. Gaussian Inc, Pittsburgh, PA, 1998

19. Zare, K.; Shadmani, N.; JNSC, 2013, 72, 1-6.

20. Zare, K.; Shadmani, N.; Pournamdari, E.; JNSC, 2013, 75, 1-6.
21. Zheng, Q.; Jiang,Q.; Phys. Rev. Lett., 88(2002).

22. Dalili, N.; Zare, K.; Gharib, F.; Shadmani, N.; JNSC, 2011, 2, 213-217.

23. Samanta, S.K.; Gomathi, A.; Bhattacharya, S.; Rao, C. N. R.; Langmuir. 2010; 26, 1223012236.

24. Zare, K.; Shadmani ,N.; Yousefian, Z.; Nano Chemical. Agriculture, 2014, 1, 94-99.

25. Moradi, O.; Zare, K.; FULLER NANOTUB CAR N, 2011, 19, 628-652.

26. Lee, C. H.; Zhang, D.; Yap, Y, K; J. Phys .Chem. C. 2012,116,1798-1804.

27. Chen, H.; Chen, Y.; Liu, Y.; Fu, L.; Huang, C.; Llewellyn, D.; Chem. Phys. Lett. 2008, 463,130-133.

28. Liu, J. Ch.; Monson, P.A., Adsorption, 2005 11, 5-13.

29. Govindarajan, M.; Ganasan, K.; Periandy, S.; Mohan,S.; Spectrochim Acta A Mol Biomol Spectrosc, 2010, 76,12-21.

30. Arenal, R.; Stephan, O.; Cochon, J-L.; Loiseau, A.; J. Am. Chem.Soc. 2007, 129, 16183-16189.

31. Konhn, W.; Sham, L. J.; Phys. Rev. A, 1965, 140, 1133-1138.

32. Shadmani, N.; MehdizadehBarforushi, M.; Shakibayifar, J.; Elsagh, A.; Zare, K.; Abbasi, Z.; Khalili, M. S.; Ahmadin, H.; Rajabzadeh, M.; Sayadian, M.; and Monajjemi, M.; J. Comput. Theor. Nanosci, 2016, 13, 208-219.

33. Shadmani, N.; Monajjemi, M.; Zare, K.; J. Comput. Theor. Nanosci, 2016, 13, 378-387. 